\title{
Waste management in the built environment on the basis of decentralization and integration strategies: the 'urban metabolism'
}

\author{
A. van Timmeren \\ Delft University of Technology, Faculty of Architecture, Climate Design, \\ The Netherlands
}

\begin{abstract}
Ecological and environmental conditions in and around cities are under pressure: transportation distances grow, protection and qualities diminish, and infrastructures (including management) get more complex, less robust and less visible, which result in a decline of sustainable commitment and behaviour of users. Yet, citizens are concerned that environmental degradation is affecting the quality of life in their neighbourhood. Resource reduction strategies and integrated waste management in close collaboration with urban planners, infrastructure developers, and representatives of key social groups are the basis to achieve environmental improvement. To do so the option of interconnection of the most important so called 'essential flows', especially waste related flows, energy, water and nutrients, at scales closer to users is argued to be necessary. This will be the guideline for urban planning based on the 'urban metabolism'.

This paper will focus on the options for improving the sustainability of the urban metabolism by interconnecting these essential flows and thus closing cycles at lower scale levels within the built-up environment (decentralization). This will be done from the perspective of the 'sanitation flows', consisting of waste water and solid waste flows in residential urban areas. After a short introduction on cycles existing sanitation infrastructures and waste management will be drawn up. Subsequently future developments will be analysed and form the basis of a new approach to waste in urban residential neighbourhoods. It promotes sustainable management of the environment and its resources through a renewed focus on waste flows (mostly ignored resources) in urban neighbourhoods and local 'quality-cascading', together with niche planning to improve knowledge on the interactions between natural resources, human activities, waste and environmental impact. The approach is illustrated with two case studies.
\end{abstract}

Keywords: decentralized waste management, integration strategies, cycles. 


\section{Introduction}

Over the past time we have built on this earth patterns that derive from attitudes about the nature of earth and the human relationship with it, and are based on a forced view of the 'make-ability' of the environment. For our culture to survive, for the human environment to become sustainable, we will have to change some of those patterns, which means changing not only our behavior but our environment. This implies change in almost every area; our cities, our landscapes, the connecting infrastructures, and especially in the reciprocal relation between cities and hinterlands, culture and nature.

Cities are like organisms, sucking in resources and emitting wastes. The larger and more complex they become, the greater the necessity of infrastructures and the greater their dependence on surrounding areas, and last but not least, the greater their vulnerability to change around them. With recent and coming perturbations of the weather as well as constantly increasing demand of energy, water and materials, this aspect of vulnerability and dependence is becoming essential for sustainability, as the world may be entering a period of scarcity. Therefore, a renewed look on the urban metabolism is necessary.

There are several strategies to cope with sustainability and the increased dependence and vulnerability. In general due to the urgency it comes down to "effectiveness before efficiency". More specific, two future paths could be determined. Within the globalizing world, centralization through interconnection of sustainable (re)generation and (re)use, connecting sustainable solutions in the different regions, and especially balancing both hemispheres is one. The other option is exactly the opposite: decentralization, trying to interconnect supply and demand sustainable on smaller scales, near to users, and therefore near to the origin of environmental problems, and potentials [1]. This latter future path will be the subject of this paper, focusing on the waste and waste water flow in the built environment. The presented research is commissioned by the Delft University of Technology (TUD) in the Netherlands as part of the D.I.S.C. Research Programme (Design Integration of Sustainability \& Comfort) of the Climate Design \& Sustainability chair (CD\&S) at the Faculty of Architecture.

\section{Permanent cycles}

The presented research attempts to contribute to "cyclic thinking" and "cyclic design" in the (actual) built-up environment, with as little as possible extra work, energy, waste and capital as a starting point. It focuses mainly on the second step of the three-step model by the Dutch authorities concerning sustainable development: (1) extending energy consumption; (2) closing of cycles of 'materials / nutrients' and (3) supporting quality / life span of products.

A cycle may be part of one or more ecosystems. Usually, ecosystems are defined as parts or areas in a more or less isolated state that are capable of preserving their own balance, always open to influences from outside [2]. In this study, ecosystems are considered as natural parts of technical systems (e.g., buildings, districts or towns), in their turn being elements (parts) within larger ecosystems. The scope of this study is formed by the most important flows 
related to the first necessities of life, viz. energy and sanitation, which implies energy, water and waste. Systems are called "sanitation systems" (after the French "sanitaire", meaning "health" or "hygiene") if the systems concern the flows dealing with health aspects. In this study, for reasons of the importance of the organic part of the solid waste, we adhere to the general definition of sanitation: waste water systems and solid waste.

The sanitation subflow 'waste' is described as those elements or materials that are left, together with one or more products from a production process or after consumption, and that have no market value in the current market circumstances. By now, waste actually almost always is a product, since it has become to represent an important and increasing market value, and there are markets at regional, national and international levels.

Within the area of "water", a sanitation system contains: the entirety of the water chain, viz. the collection, production, distribution and use of drinkingwater, the collection and use of rainwater, facilities for toilet water and use of water in housing, the collection, transport and processing of refuse, discharge and/or dumping/reuse. The "urban water cycle" is defined as a cycle, but is not a (closed) cycle: it is part of larger cycles. Drinking-water and waste water form the elements of the so-called "small hydrological cycle" within the "large hydrological cycle". It is not necessary that the small water "cycle" is defined as a closed cycle. It is better to consider it as consisting of various (created and) interrelated "small cycles", including nutrients, energy, carbon, metals. The urban part is only one of the parts in the cycles concerned. Each of these small hydrological "cycles" can be repeated many times, but strictly speaking is not to be defined as a genuine cycle. Then, the objective of sustainability can be set thus: the urban system is not allowed to exhaust or overload the surroundings. In this point of view, it is not necessary for the urban system to be fully autonomous. However, if the created "small cycle" is not closed at an urban level, town and surroundings should be complementary, so that they can minimize the environmental load together.

\section{Existing sanitation management in the built environment}

The sanitation system, including the treatment of solid waste, in general is organized in a central way. The centralized character and the necessary transport over long distances imply a use of relatively many raw materials, energy $[3,4]$, and chemicals, and a higher intensity of building material [5]. They also make use of a large quantity of high-quality tap water as a means of transport. The main disadvantage is that a relatively complex waste water flow arises, because the various water flows with various degrees of pollution mixed with (valuable) drinking-water get into the sewer. The purification of this relatively complex waste water flow is difficult. The organisms and substances that are risky for public health and were originally concentrated in a small volume of waste (faeces) are drained in a large (waste) water volume often over long transport distances in very much diluted form and spread over the environment. Another (increasing) problem with the accompanying health risks originates from the fact that faeces and other secretions are carriers of hormones and micro-organisms 
that can be resistant to antibiotics, and of antibiotics that are left from medical treatment and meat production. These medical residues and hormones with a good polarity accumulate in the settled down biomass in the waste treatment plants, under high density and favourable circumstances, and multiply the resistance for antibiotics and even develop multiple resistances [6,7].

Summarizing the disadvantages one could say that a large volume of relatively less polluted waste water undergoes unnecessarily long and complex purification steps. The risks and consequences of centralized systems dysfunctioning because of mixing various drainage flows are large. In case of calamities, it is less easy to disconnect part of the present central systems (to isolate the problem) in order to make the area of distribution (of the problem) smaller.

In the twentieth century also much of the solid waste related flows was changed, particularly with respect to the waste processing of homes. At the beginning of the century, the environmental hygienic problems caused many municipalities to found their own sanitation departments. At the same time, the amount and complexity of the waste and of waste regulations increased enormously. Roughly, there are three processing options for the mixed, or "grey", solid waste flow. First, there are the waste treatment plants, where the flow is divided into subflows each of which are processed in a different way: a high-energetic (or caloric) fraction, a low-energetic fraction and a fraction with paper/plastics/ steal/other metals. The high-energetic fraction is sent to the incineration, the low-energetic fraction goes to a washing plant, after which the metals are separated for reuse. Finally, the third fraction (the mix of paper and plastics) is processed further by the paper and plastics industry. The second option is the incineration plant. This is considered the most expensive method of solid waste management. In order to prevent any air pollution, the waste treatment requires expensive after-care. Finally, the waste can be dumped. This, however, has severe environmental disadvantages: there will be a lack of space, and the dumping causes an uncontrolled emission of greenhouse gases, possible soil pollution and the leakage of dangerous substances into the groundwater.

In 1980, the Dutch government published a general preferred order for the removal of waste as part of the National Environmental Policy Plan, now used internationally. This preferred order is called "Lansink's Ladder". There is consensus about the order. The concrete goal of the waste control in order to achieve this preferred order however is controversial. This is caused by the fact that the system of market protection, based on "capacity planning with a truck system", has two dimensions. First of all, the "vertical dimension", the policy question on which step of "Lansink's Ladder" the waste is processed. Second, the "horizontal dimension", the policy question at which location processing takes place [8]. The last few years, a renewed discussion takes place about revision of the notion of waste. The background is the need for a Level Playing Field in Europe, the arbitrariness in the present rules and regulations, judgements of the European Court, the economic implications of waste treatment and renewable scientific renewable scientific views. A division into two main categories is suggested [9]: 
- "waste for removal", dangerous waste (permanent storage or burning if possible) and unusable waste (functional storage);

- “waste for recovery", combustible waste (for generating energy) and reusable waste (secondary materials, semi manufactured products).

Roughly, the waste market can be divided into three submarkets, each of which corresponds with one or more phases of the waste chain or waste treatment chain: the collection of waste, the recycling and the waste treatment and sales. The monitoring of the compliance with the (environmental) rules is crucial, especially since waste processing companies get their income when the waste comes in (and, consequently, not when they sell their products). "Nothing venture, nothing gain" does not apply here, so that trading results become higher when no or hardly any costs are made.

As in most other European countries, gradual liberalization of the segment takes place, and as a result there is so-called competition "for the infrastructure" (or "for the market; as opposed to competition for the infrastructure or competition between infrastructures, which plays a role in case of the other infrastructure related segments, or may do so): municipalities that put the collection of domestic waste out to tender, whether or not collectively.

The processing of waste in Western Europe has the following characteristics:

- $\quad$ promotion of hygiene;

- centralized organization for collection and treatment of general waste and organic waste;

- own (individual) initiative for collection of other subflows (recycling of paper, cork, babies' napkins, tetra cartons, bottles, plastic flasks, etc.), centralized transport and treatment, and no level playing field at a national and international scale level;

- many participants; a varying number of participants playing a role in the guiding of waste, complex contact patterns, and independent, strategic behaviour (e.g. "threatening" with import from abroad in order to promote rebalancing of waste over production or treatment capacity. Also, new techniques, such as fermentation, are sometimes approached in a negatively critical way in order to protect waste incinerator plants, and some authorities consciously ignore the ban on dumping in order to be able to finance after-care);

- protection of the environment through accentuation of optimum reuse of (raw) materials;

- European harmonization (e.g. the transition from the deposit principle to the principle of waste disposal fee);

- $\quad$ possibilities for differentiation of products and services;

- formally legal "quasi-regional self-sufficiency" (in practice, actually a balance on paper rather than in reality); 
- limited possibilities for transport over long or longer distances, evaluation and decisions in governmental hands and on an individual and ad hoc basis.

In summary, this may be described as a paradigm consisting of a centrally regulated collection, transport and treatment (production). In this treatment system, the following "technological paths" (choices) are decisive:

- The most frequent solution for the treatment of organic waste is (still) composting; fermentation is applied in exceptional cases. The last few years, there is a large shift from composting to incineration because of an increased pressure from energy supply.

- The usual solution for the other waste is incineration. In the Netherlands, like in more and more countries, waste dumping is only exceptionally done; there is dumping (by exemption) or export only in exceptional cases.

- Increasing large-scale nature, complexity and dynamics. Relations of ownership and divisions of regions cannot keep up with the scaling-up, and incidents determine actions.

- Treatment is (still) mainly in governmental hands, directly or indirectly, but there are large transformations in the composition of the various parties and the parts of the chain they are controlling.

The past few years, the latter aspect is changing strongly, since a larger and larger part of waste treatment is being put out by the (as yet responsible) municipalities to (fully independent) commercial parties.

\section{Future developments and alternative arrangements}

In the (solid) waste sector, we see a gradual decrease of (totally) treated waste and a strong rise of reuse of waste materials. This is also caused by the fact that a large part of our waste is organic waste. This can be transformed into bio-gas (methane), compost and sludge (fertilizer) "close to the source" by means of composting and fermentation. No use or (too) little use is made of energy generation through the production of, for example, bio-gas, and through reduction of the waste flows to be transported. Further-reaching investments in the reprocessing of waste into fuel by means of fermentation in large biomass plants seem to overshoot the objective. In practice, there is the problem of a double orientation and the complex situation leading to strategic behaviour, suspicion and lack of understanding between the parties involved. As a consequence, a balanced process of interweaving of goals within Western Europe has failed to occur, as opposed what has happened to some extent in the energy market, for example [8]. The very complex character of the waste sector is responsible for this. One of the goals now is to simplify this situation structurally. At the same time it is important to note that the risks of simplifying are: the problem definition being too much limited, the lack of information, the relatively sub-optimal solutions to which it leads, any social resistance and 
problems, and the lack of support "in the field. The approach focuses on the better facilitation of changes by means of:

- $\quad$ narrowing the policy process;

- limiting the number of parties involved;

- $\quad$ increasing transparency, splitting up policy processes;

- $\quad$ fitting in with alternative types of administration.

Gradually, the business dimension is being released (free-market system): by following the scale size of the servicing areas, that has arisen, and the free competition, e.g., between waste incinerators and dumping sites, but also of requested user(groups), i.e. decentralized entities. The aspects related to "public good" are covered in such a "conditioned system" of a free-market system by the possibilities of testing capacities and taking price control measures, e.g., in case of monopoly or oligopoly.

Macro-economically, a "level playing field" is being organized (or aimed at) in the European Union: suppliers and waste processors can become active elsewhere within the European Union (the borders for combustible, not dangerous waste will be open).

At the moment, many waste-processing companies are considering their strategic options: expansion, chain integration and/or technological innovation.

The emphasis is on chain integration and the internal adjustment of the various parts of the organization (culture, systems, etcetera).

There is also a process of diversification going on. In this, the chain integration has two lines of approach:

- forward chain integration: end processors will concentrate on activities earlier in the chain, e.g., collection and recycling;

- backward chain integration: waste collection companies will concentrate on recycling, dumping and/or incineration of waste flows.

Nevertheless, the governmental involvement in the waste market and waste removal market will continue to focus on the embedding of the "element of public utilities", the protection of bound users and the promotion of equal chances. There will still be a "conditioned free market". On the one hand, the scale sizes as to the way tasks are carried out will continue to increase; on the other hand, more decentralized control models (i.e. administrative decentralization) might be applied because of the intention of "shared public responsibility". Within this general changes in waste management specific strategies, like the Cradle to Cradle approach [10] and innovative decentralized concepts (i.e. technical decentralization) [1] will become more and more directive. A 'whole-life system' approach to resource use and 'product' design has the potential to ensure that, in terms of the ecological impacts and efficient use of resources, the product gets better as it goes through the system.

Outset is that products (including buildings) can be designed so that, after their useful lives, they will provide nourishment for something new, being 
'biological nutrients' or 'technical nutrients' that will continually circulate as pure and valuable materials within closed-loop industrial cycles (rather than being recycled). When socially, economically or technically impossible, the nearest alternative for this cradle-to-cradle approach is the cascading use of resources where high-grade flows are used in high-grade processes and residual waste flows are used in lower-grade processes, thus making the most efficient use of the initial value of a resource. This so-called "low-exergy approach" (exergy is used here in a wide meaning) is of rising importance and is inspired by natural ecosystems, and thus in line with the "Industrial Ecology" thinking. At the same time it is important to realise that there are irreducible limits to recycling. Materials dissipate in use and recycling. Recycling is not $100 \%$ efficient and can have detrimental impacts. This means that materials may in the end become more crucial than energy.

Science, and increasingly the market too, bring up a rising number of solutions that imply possible smaller scales of implementation. The considered benefits are a possible reduction of infrastructure (and related actions, like collection/ transportation) and better visibility and tuning into the demand, and, therefore, more flexibility. Especially in the field of organic waste connected small scale Combined Heat Power generation and ecological sanitation systems, important efforts have been made. The latter, so-called DESAR (Decentralised Sanitation and Reuse) systems, offer an alternative for the current status quo.

Otterpohl [11] claims that such efficient decentralized sanitation concepts will largely have to be developed together with environment-minded agricultural and energy concepts, as integral concepts of "Urban Agriculture", in order to make direct reuse (near the source) of water, energy and nutrients possible by users or product developers and producers. Advantages of "urban agriculture" are environment-technically: $\mathrm{CO}_{2}$-reduction, possibility of ecological corridors and "islands" in the built environment, applications for composted organic waste close to the users; socially: possible support of local economies, leads for social embedding and integration projects, education and recreation close to the homes.

Decentralized sanitation systems are usually based on a different relation between the user and waste(water) and on a different way of gaining awareness. Niemczynowicz [12] refers to this in relation to the built environment as the new (technical) paradigm in three steps:

1. find out whether the pollution can be prevented;

2. find out the possibilities for cleaning up at the level of homes or lots;

3. collect the polluted elements and take them out of the area and dissolve them.

As to the waste water and organic waste flows in connection with users, it is of importance to regard faeces as a composition of various useful materials, rather than as a useless residue in such a new technical-spatial paradigm. This implies that the waste flows and waste water flows should be kept as concentrated as possible and that it should not be diluted with (drinking-) water. An additional consideration from the angle of the generally accepted three-step approach "Reduce - Reuse - Recycle" is that an early division according to 
quality is of decisive importance. Apart from that, critical to the implementation of these concepts of integrated resource management in the urban environments is knowledge dissemination, including strong feedback systems between the different physical scales (site, neighbourhood, city-region) and strategic/smart concepts that focus on improving existing recycling efficiencies.

\section{Implementation in case studies}

The use of decentralized sanitation systems at district, neighbourhood or local scale could introduce new urban functions, options for self-sufficiency (for energy, water and nutrients) of public buildings or entire districts and improved commitment of users. The discussed option of integration of a 'combined waste (wastewater) / energy system' for an urban neighbourhood has been elaborated for two districts, which will be presented more closely in the oral presentation. First of all within an actual realised project: the deep green district "Lanxmeer" in Culemborg, the Netherlands. Secondly, as a case study, concerning the highdensity district of "Noordereiland" in Rotterdam, the Netherlands.

The first district, Lanxmeer Culemborg, consists of 250 houses (final part under construction now), several offices and a 'City farm'. The district is situated in an ecologically sensitive area, because it concerns a drinking water extraction and retention area. Essential is the integrated approach, closing cycles of nutrients, water and carbon and integration of energy generation and waste management through cascading qualities and use of the concept of exergy through collection and waste management at a decentralized scale level (Figure $1)$.

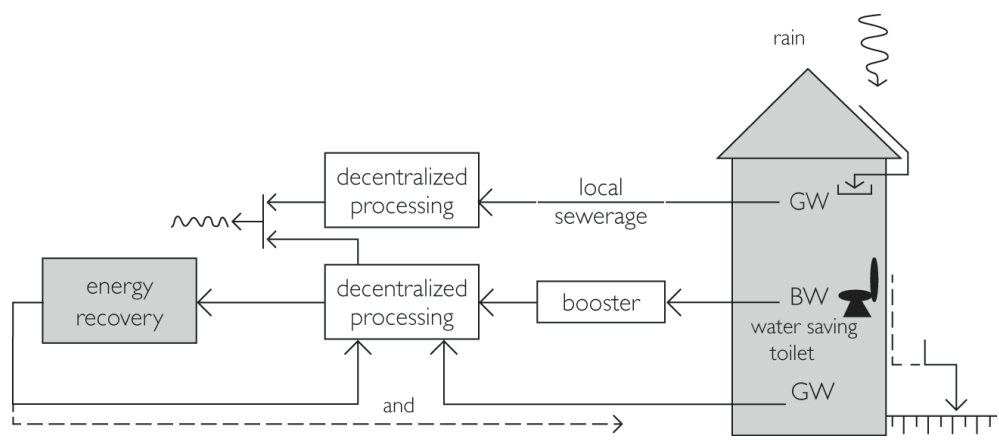

Figure 1: The chosen transportation option for waste waters (GW grey water; BW black water and GW Green/organic domestic waste) in the Lanxmeer, Culemborg district.

Principally, the concept of combined decentralized systems is based on anaerobic digestion (with treatment of 'black waste water' and organic waste/garden and park waste), Combined Heat Power (CHP). An accompanying closed greenhouse, designed as a four storey high double skin façade of the semi-public building, with integrated wastewater treatment for parts of the wastewater flows based on the Living Machine concept is added for educational purposes. In this vertical green house with 'hanging gardens' heat (and water) 
recovery and use of the surplus $\mathrm{CO}_{2}$ of the biogas plant takes place, together with heat/cold storage in an underlying aquifer. The concept is called 'Sustainable Implant' (Figure 2).

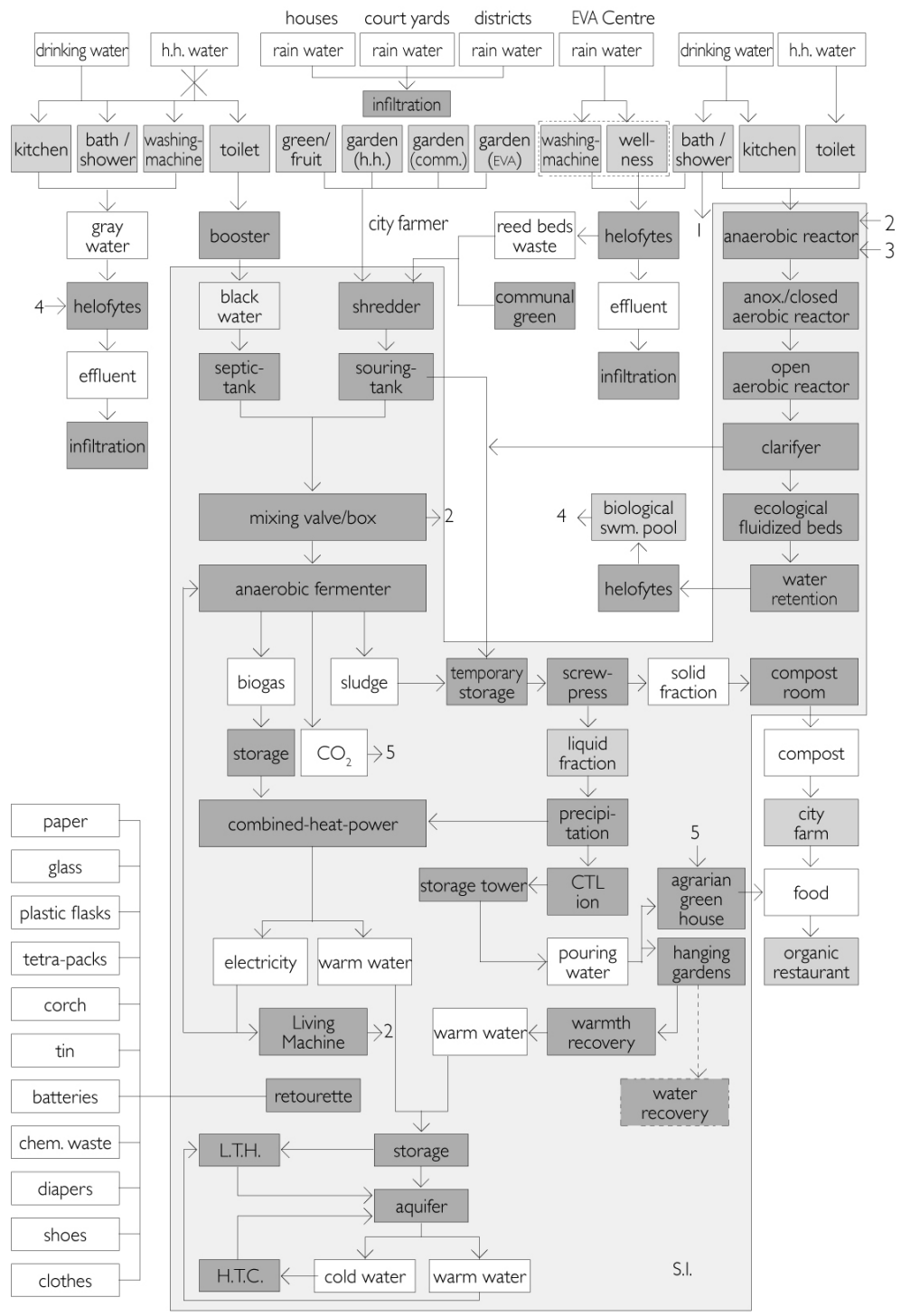

Figure 2: $\quad$ Scheme of the treatment and cascading of the different waste and water-related flows of the EVA-Lanxmeer district in the Sustainable Implant (or in short: S.I.).

The S.I. will be realized as a part of the EVA Centre, an ecological information and education centre and has an interconnecting role between both residential district and EVA Centre, inhabitants and visitors. 
The introduction of solutions on an intermediate scale-level, like in Lanxmeer, Culemborg, offers opportunities for autonomous design of the entire district or elaborations in which buildings can be (semi-)autonomous on the basis of wastes of a (neighbouring) district. The appealing-, and partly realised, example of the linking of agriculture, waste(water) treatment and energy production might be exemplary for the potentials of the supposed need for a change in attitude [13].

To make the formerly explained approach tangible and even more relevant a decentralized water system, with additional emphasis to the water component, has been designed for an existing city district: the "Noordereiland" in the Dutch (seaport)city Rotterdam. The Noordereiland is a pre-war housing district (approx. 3600 inhabitants in 1900 households), situated on an island in the river "Maas", and forms an important link between both sides of the river. The islanddistrict has a (for the Netherlands) high housing-density of 94 houses per hectare [14].

The sewerage system of the island now is connected with the system on the northerly area (one of the two main sewage systems of Rotterdam) and forms a dead-end of this side of the grid. The water cycle of the Noordereiland at the moment has an extensive reach and is known to be a heavy burden for the direct (and surrounding) environment. The background for the introduction of an independent and sustainable waste water and organic waste processing in this "enclave", is that is will improve the overall robustness of the waste (water) processing of the city, an actual problem, especially at moments of heavy rainfall. As the latter due to climate change is even expected to increase strongly, in number and intensity, the presented approach fits well within the current strategy of "climate robust planning strategies" (ARK) of the Dutch government.
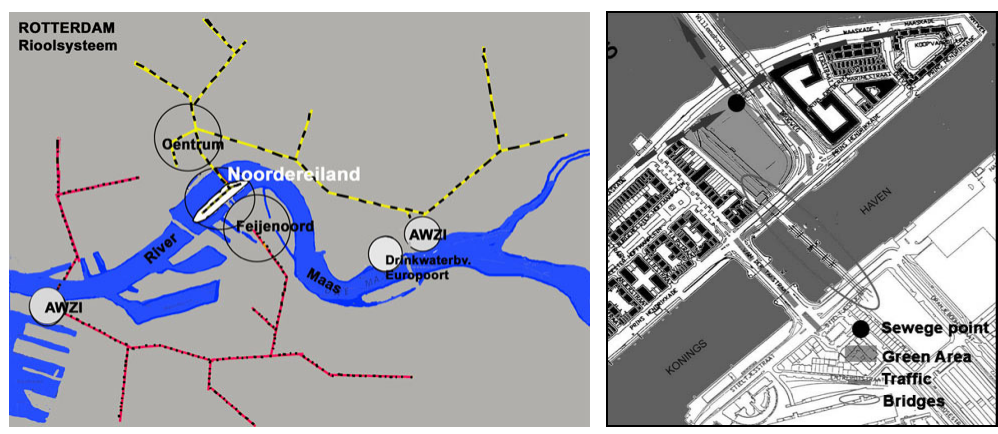

Figure 3: $\quad$ Map of the two existing centralized sewage systems, and of the area in the Noordereiland where the proposed organic waste (water) system of the island is located.

The 'environmental effects' (among which the energy content, the use of chemicals, use of water and use of waste/materials) of the overall (waste)water flows (treatment, retention, etc.) of the entire city district is reduced significantly. Besides of that the upgrading of the existing non-functioning and final (green) 
open urban area in the district improves the overall liveability of this highdensity district while coupling it to economical and natural innovative functions.

\section{References}

[1] Timmeren, A. van, RECIPROCITY of Autonomy \& Heteronomy. Decentralization vs. Centralization of essential services in the built environment. Research in Urbanism Series (RIUS), IOS Press, Amsterdam, (release June-) 2008.

[2] Tillman Lyle, J., Regenerative Design for Sustainable Development. The Wiley series in Sustainable Design, John Wiley \& Sons, New York, 1994.

[3] Werner, C., A holistic approach to material-flow management in sanitation. EcoSan Conference "Closing the Loop in waste water management \& sanitation, Plenary session 2, Bonn, 2000.

[4] Leeuwen, J.J.W. \& Meijer, H.A.. Duurzame Stedelijke Waterkringloop. Illustratie proces DTO Werkdocument W1, Interimrapport, Delft 1996.

[5] WIMEK Decentrale inzameling en behandeling en hergebruik van huishoudelijk afvalwater. Wagenings Instituut voor Milieu- en Klimaat onderzoek, Werkgroep DESAH, WUR, Wageningen, 1996.

[6] Daughton, C.G. \& Ternes, T.A., Pharmaceutical and personal care products in the environment: Agents of subtle change? Environmental Health Perspectives, Volume 107, Supplement 6, 1999.

[7] Dorau, W. \& Schönfeld, A., Hygienic safety and water re-use potential increased by means of bio-membrane-technology EcoSan Conference "Closing the Loop in waste water management \& sanitation, Bonn, 2000.

[8] Baas, J.H., Hectiek en vereenvoudiging van besturingscontext. Afvalbeleid in Nederland naar een nieuwe ronde. Bestuurskunde themanummer 'Afvalbeleid bestuurskundig beschouwd', Jaargang 7, nr.5, 1998.

[9] PWC, De nieuwe afvalmarkt: grenzeloze mogelijkheden? Afvalseminar 2004, PriceWaterhouseCoopers Netherlands, 2004.

[10] McDonough, W., Braungart, M., Cradle to cradle. Remaking the way we make things. North Point Press, New York, USA, 2002.

[11] Otterpohl, R., New developments of EcoSan in Germany and Europe, EcoSan Conference "Closing the Loop in waste water management \& sanitation, Bonn, 2000.

[12] Niemczynowicz, J., Ways to overcome barriers against applications of "new technical paradigm' in cities. Presentation International Workshop "Hydropolis", Wageningen, 1993.

[13] Timmeren, A. van and Röling, L.C., Introducing Urban Agriculture concept in Urban Planning: The 'Park of the $21^{\text {st }}$ Century'. Proceedings Int. Conference Sustainable Building (SB05), Tokyo, Japan, 2005.

[14] Meijer, B.M.A., Timmeren, A. van, Integral restructuring of an existing high-density city-district through the introduction of a decentralized (waste)water and energy concept. International Conference The Sustainable City, Siena, 2003. 